\title{
Germplasm enhancement for adaptation to climate changes
}

\author{
Marcelo J Carena $^{1 *}$ \\ Received 2 April 2011 \\ Accepted 29 May 2011
}

\begin{abstract}
Billions of dollars and crops are being lost to drying high moisture grain; drought, cold, and salt susceptibility; and to processing poor quality grain. Maize is a model crop for adaptation to climate changes. Breeding for adaptation is best done under challenging environmental conditions where strengths and weaknesses are quickly identified and most stable genotypes are selected. The North Dakota State University (NDSU) maize breeding program is strategically located to develop products under extreme weather. It currently exploits northern U.S. environments that allow screening for adaptation traits that are as important as yield. The program focuses on germplasm adaptation and its integration into cultivar development, particularly those carrying unique alleles not present in the B73 and NAM genomes. There is a need for projects that are vital to agricultural research and will meet present and future demands of superior genotypes tolerant to climate changes in the U.S. and abroad.
\end{abstract}

Key words: adaptation, cultivar development, genetic diversity, maize breeding, NDSU EarlyGEM.

\section{INTRODUCTION}

There is a need for innovative agriculture critical programs of national scope. 'Cutting edge' has attracted funds and investigators to conduct similar research which is not innovative. Public sector breeding programs continue to disappear across the U.S. and abroad because of changes in research emphasis. Since 1999, I have been the third breeder contributing to over 80 years of NDSU maize breeding research focused toward the development of short-season (65-95RM) products. The breeding program is known for being the most northern public maize breeding program in North America and one of the few active U.S. maize breeding programs with strong stakeholders support. The program has the uniqueness to conduct applied research that ends with inbred line and population releases, which is unique for training the next generation of applied plant breeders. The NDSU maize breeding program is one of the few public programs that can still offer a strong emphasis on germplasm adaptation and improvement, inbred line development, hybrid identification, and training of applied plant breeders.

Most northern U.S. industry hybrids are not locally bred for very short seasons such as North Dakota (ND). This is due to environmental challenges that are similar to climate change claims. This makes northern U.S. environments ideal for directed evolution through breeding and, therefore, unique for developing maize products adapted to climate changes. The need for hybrids adapted to very short seasons, with drought and cold tolerance, fast dry down, and enhanced quality justifies the need for applied public breeding programs in the area while staying ahead of climate changes.

\footnotetext{
${ }^{1}$ North Dakota State University, Department of Plant Sciences, Dept. \# 7677, Fargo, ND 58108-6050, USA. *E-mail: marcelo.carena@ndsu.edu
} 
The NDSU maize program focuses toward expanding maize north to cooler seasons and west to dry areas. It acts as a genetic provider to foundation seed companies, retailer seed companies, cooperatives, processing industry, and public breeders nationally and internationally. Since 1999, NDSU was awarded nine PVP corn certificates, released 12 products (four populations and eight inbred lines), and provided 11 experimental lines and four populations to foundation seed companies and other cooperators for commercial hybrid production (Carena and Wanner 2003, Carena et al. 2003, Carena 2005b, Carena et al. 2008, Carena and Wanner 2009, Carena et al. 2010). We develop diverse and unique products not only for areas of heavy industry investment, but also for areas of low to zero industry investment, providing service to all ND and northern U.S. farmers equally independent from their farm location and hybrid market. Public and private institutions have either cooperated with the program on research of mutual interest or have utilized its products. In kind cooperation from industry and western research centers (Williston and Hettinger in North Dakota; and Sidney in Montana) have allowed us to increase our testing and breeding network to 24 locations and $\sim 25,000$ plots, and 20,000 winter and summer nursery rows annually. Winter nurseries have, in certain cases, reduced in three times the timeframe for maize genetic improvement due to the shortseason nature of the program. Industry partnerships have allowed us to access expensive technology (extractable/ fermentable starch screening, doubled-haploid production, SNP markers and high throughput genotyping, drought and cold-controlled environments, NIR calibrations, etc.) and access to breeding rights, checks, testers, trait events, and research locations which has saved NDSU significant research monies, labor, and especially time annually. This cooperation has avoided spending federal and state grant monies to invest in expensive academic labs that become obsolete very quickly. However, exclusive agreements and other confidential limitations to breeding access still prevent the development of the ideal cultivar. Currently, industry protected lines could be improved locally for providing either an improved male or female version of a better hybrid to farmers. An ideal maize system to provide better breeding chances to public breeders has not been developed yet and could be proposed for areas with climate change concerns. Private breeders have had access to public germplasm in the past but this is changing toward more protection as well.
The NDSU maize breeding program targets traits in order to reduce the current gap between conventional breeding and utilization of proven successful technologies. This should help develop cultivars adapted to climate changes. Marker-assisted selection and/or genome-wide selection are tools that were originally designed for low heritable economically important traits that are difficult to measure. These tools, however, have not been successful for screening these quantitative traits (Barata and Carena 2006, Sonino et al. 2007, Hallauer et al. 2010). Instead, they are being proposed to be used in traits that are very easy to screen and select for at minimum cost (e.g., flowering time, Eno and Carena 2008, Hallauer and Carena 2009, Hallauer et al. 2010). These tools could be useful for simple traits that are difficult to measure (e.g., underground traits such as cyst nematode in soybean). However, without choosing, sampling, and locally adapting the right germplasm to climate changes neither traditional breeding methods nor any modern technology will succeed.

\section{BREEDING FOR LOCALADAPTATION TO EXTREMEENVIRONMENTS}

In ND, the number of growing degree units, average low rainfall (especially as we go west), and the high frequency occurrence of early frosts are important environmental challenges facing regional maize producers. These producers are either located in areas poorly served by industry or are offered products usually developed elsewhere and, as a consequence, not adapted and/or stable to these environmental challenges. ND leads the expansion of U.S. maize acres approaching 3 million (e.g., less than $1 / 2$ million acres 10 years ago). Still most northern U.S. industry hybrids are not locally bred since they are mostly provided by retailer companies. These companies license shortseason lines and hybrids indirectly from genetic providers through Foundation Seed Companies located mostly in southern Minnesota (MN). Therefore, these hybrids are often late-maturing products with below average grain quality, drought and cold tolerance, and rate of dry down. Clearly, this is the reason why hybrids are not dependable and stable over environments which makes them extremely vulnerable to climate changes as it has especially been shown in 2004 and 2009 (abnormally very cool season). In addition, the lack of active industry presence for breeding substantiates the need for programs addressing the development of new cultivars adaptable to climate changes. It is not been easy to expand to areas with 
constant challenging environmental conditions. Breeding programs addressing climate change challenges are essential for the future sustainability of maize production not only in current maize production areas but also in areas where maize production is headed.

The NDSU maize breeding research program goals are to adapt elite exotic germplasm, to maximize the genetic improvement of adapted germplasm, and to develop elite and unique cultivars. Breeding for early maturity, abiotic stresses, and grain quality are top priorities to meet the future demands for food, feed, fuel, and fiber in changing environments. The program adapts elite and unique germplasm resources through most efficient (cost/benefit) breeding strategies. Breeding methodologies are complemented with managed-stress winter and summer nursery environments (e.g., high elevations for cold tolerance, soil salinity patterns, and areas with no rain and irrigation for stand establishment and stress control) for short-season cultivar development. Multi-trait selection, multi-stage testing, and multi-progeny evaluation of recurrent selection and testcross trials are common procedures for discarding thousands of progenies and identifying top ones with specific genetic effects for climate changes. Each successful hybrid has its own unique combination of genetic effects. Often sample sizes for basic science experiments (e.g., QTL experiments) are limiting relative to classical quantitative genetic studies. Mating designs are utilized for producing progenies (large sample sizes) and genome sequence information could complement 'traditional' quantitative genetic studies on double-haploid and other breeding populations. Also, breeding programs adapting and improving genetically broad-based germplasm could provide national labs unique genetic materials for additional sequencing efforts to increase the sample size currently limited by B73 and NAM populations. The goal would be to identify unique alleles for climate changed. Few of these unique programs with extensive recurrent selection programs are left that could validate simulated models for new selection methodologies.

Unlike expensive genomic efforts on isolating earlymaturing genes and/or QTLs, significant genetic progress has been achieved, without exceptions (across populations), at a rate of 2 to 3 days earlier per year (Carena et al. 2008, Eno and Carena 2008, Hallauer and Carena 2009) by screening 20,000 to 25,000 plants per population cycle with a very simple approach at less than one penny (\$0.01) of screening cost per plant demonstrating the use of cost efficient successful tools after good choice of germplasm.
This is a major improvement in adaptation considering indirect selection for quantitative traits was also successful. Figure 1 shows the uniqueness in the sources of materials used by the NDSU maize breeding program for inbred line development.

\section{The NDSU EarlyGEM Program: Increasing the Genetic Diversity of Northern U.S. Hybrids}

The climatic patterns and market demands keep changing, especially in ND. A solution to these uncertainties is to maintain breeding programs open, keeping useful genetic diversity at maximum. The NDSU corn breeding program integrates pre-breeding with cultivar development including adaptation of exotic germplasm, maximization of genetic improvement through various recurrent selection programs on adapted germplasm, and inbred line development through early and late generation hybrid testing programs starting at the $\mathrm{F}_{2: 3}$ inbreeding generation. The NDSU germplasm used as a source for inbred line development is both genetically narrow and broad-base including elite $\mathrm{x}$ elite combinations within heterotic groups, intra and interpopulation recurrent selection programs, stratified mass selection programs, and backcross incorporation programs among others (Figure 2).

The NDSU Early GEM (the Program for Early Germplasm Enhancement of Maize) represents one of the incorporation programs that exploit the challenging ND environmental conditions by adapting exotic germplasm. As one of the first members of the United States Department of Agriculture-Germplasm Enhancement Maize Project (USDA-GEM) network, the NDSU program was the first to develop tropical and temperate genetic materials adapted to the northern U.S., incorporating unique tropical and early-maturing alleles from the Latin American Maize Project (LAMP) not present in the B73 or other popular genomes (Carena et al. 2009c). As such, NDSU is the sole genetic provider of these short-season products to industry. The long-term goal of the NDSU EarlyGEM program is to increase the genetic diversity of northern U.S. hybrids through the incorporation of exotic useful germplasm and development of early maturing ( 90RM) high quality inbred lines for utilization in the northern U.S. Corn Belt. The specific objectives are:

1) Incorporate GEM germplasm as donor for high quality and genetic diversity.

2) Adapt GEM germplasm to short-season environments. 


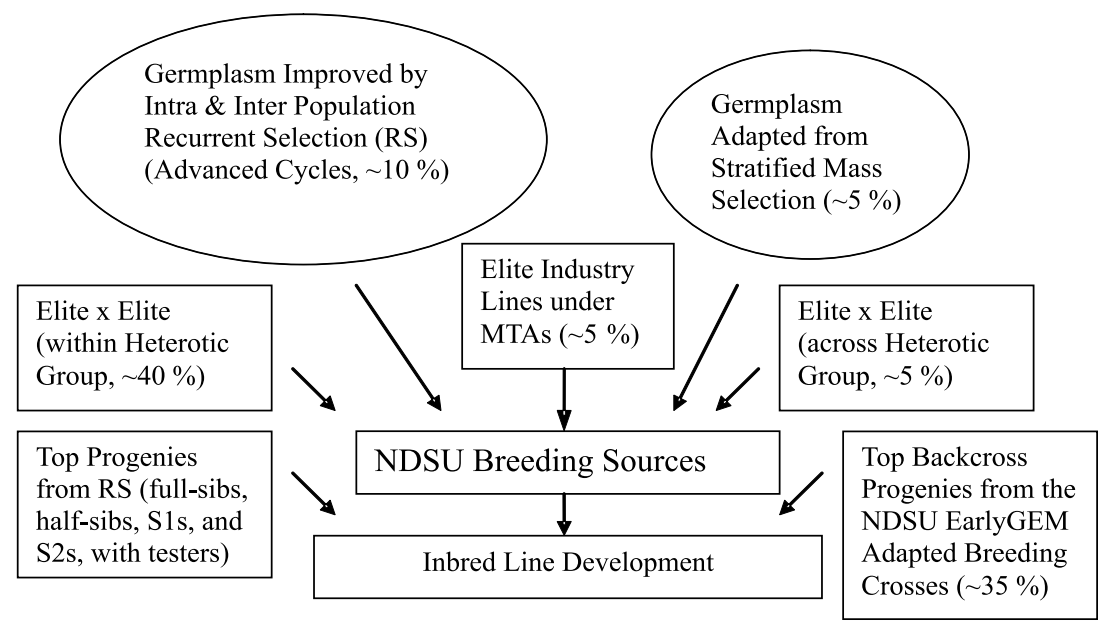

Figure 1. Germplasm pre-breeding sources for NDSU maize inbred line development (adapted from Carena et al. 2009b).

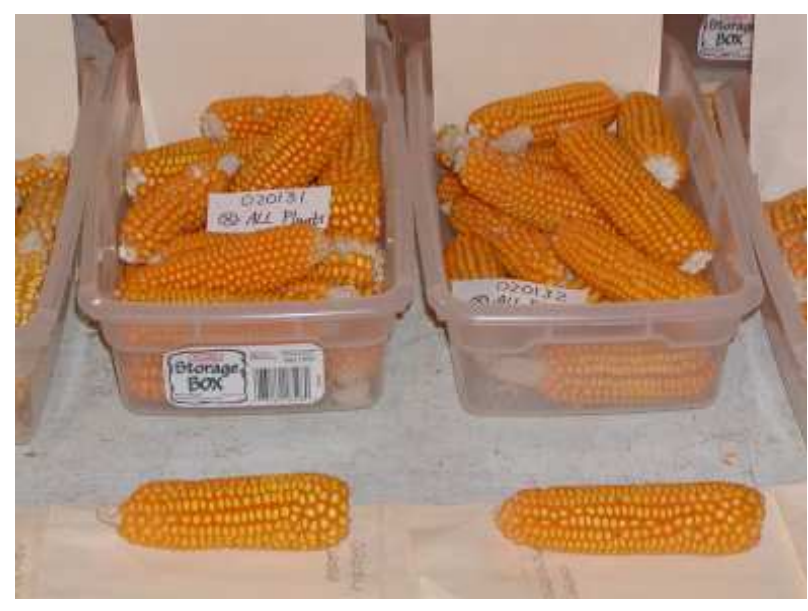

Figure 2. ND2000 early maturing line release by NDSU maize breeding program as source for early-maturing hybrids, recurrent parent on EarlyGEM lines.

3) Develop new early maturing NDSU EarlyGEM unique lines competitive for industry use.

A backcross breeding program was initiated including elite LAMP-GEM and ND lines. The inspiration of this long-term adaptation program was the backcross breeding program initiated by Dr. Pinnell at University of Minnesota (Rinke and Sentz 1961) that yielded successful Minnesota 'A' lines. However, the difference is that our program utilizes early maturing parents as recurrent ones and that only one backcross generation is produced without screening in $\mathrm{F}_{2}$ generations. Initially, over 150 GEM $\mathrm{S}_{3}$ lines from released GEM sets of wide breeding crosses were introduced to ND. The most elite and adapted ones were selected and crossed to ND inbred lines. $F_{1}$ generations were backcrossed to early-maturing lines only once. Only nine populations were kept to produce $\mathrm{BC}_{1}: \mathrm{S}_{1}$ [e.g. (GEMxND2000) x ND2000] elite early maturing lines. These consisted of Stiff Stalk (SS) donors (CUBA117:S1520-388-1-B, CHIS775:S1911b-B-B, and AR16026:S17-66-1-B) and non-Stiff Stalk (nSS) ones (BR52051:N04-70-1， SCR01:N1310-265-1-B-B, FS8B(T):N1802-35-1-B-B, UR13085:N215-11-1-B-B, CH05015:N15-184-1-B-B, and CH05015:N12-123-1-B-B) representing several Latin American country accessions. Approximately 5,000 lines were selected for inbred line development and early generation testing with industry testers. SS and nSS donors were advanced through the NDSU pedigree selection process including drought tolerance screening under managed stress environments (Carena et al. 2009b). Only ND2000 was kept as the elite recurrent parent due to its unique capabilities for earliness, dry down, grain quality, and seed production (Figure 2). Foundation Seed Company testers representing the B14, Iodent, and unrelated heterotic groups were utilized for early and late generation testing of NDSU EarlyGEM lines. Preliminary data have shown these lines to be not only 12 to 20 days earlier than original versions, but also carry greater grain yield (10.4 vs. $\left.9.2 \mathrm{tha}^{-1}\right)$, test weight $\left(72.5 \mathrm{vs.} 70.1 \mathrm{~kg} \mathrm{hL}^{-1}\right)$, extractable starch (67.8 vs. $64.2 \%)$, fermentable starch (16.6 vs. $16.4 \%$ ), grain oil (4.3 vs. $3.5 \%$ ), grain protein (10.5 vs. $9.4 \%$ ), and up to $194 \%$ greater yield under intense drought conditions in hybrid combinations, on average, when compared to top industry hybrids at similar grain moisture at harvest. Additional data, especially on nSS donors have validated these encouraging results. Adapted lines from 
tropical exotic Brazilian accession BR52051 produced hybrids with low moisture (21.8\% vs. $27.3 \%)$ at similar level of yield (LSD, 0.05) when compared to top industry checks. Similarly, derived lines from temperate accession CHO5015 and tropical accession FS8B (T) showed high grain protein (9.9\% vs. $8.9 \%)$ and grain oil (4.9\% vs. 4.6 $\%$ ) concentration levels with similar yields to top checks. Derived lines of the tropical accession DKB844 also showed to be a good source of early SS lines with high yield while lines derived from tropical accession CUBA117 showed comparable yield and higher grain protein $(10.2 \%$ vs. $9.3 \%$ ) when compared to checks. Late generation trials across 13 environments have shown BR52051 hybrids had low grain moisture at harvest (18.6\% vs. $22.9 \%)$ at similar yield levels when compared to top industry checks. Incorporating exotic germplasm has also provided new alleles for disease resistance as has clearly been shown in our 2009 Fargo-breeding nursery where the only ear-rot resistant lines under intense natural infection were LAMPGEM derived lines. The NDSU maize breeding program has demonstrated preliminary success in adaptation by investing in long-term goals (Figure 3). New short-season lines and populations with excellent general combining ability have been recently developed. Our results agree with the finding that maize inbred lines with certain percentages of non-Corn Belt germplasm often have combining abilities for grain yield greater than inbred lines carrying $100 \%$ of U.S. Corn Belt dent germplasm (Griffing and Lindstrom 1954, Carena et al. 2009c, Sharma and Carena 2011) with the advantage that exotic populations carry more genetic diversity (Goodman 1965). Rinke and Sentz (1961) considered their work as one of the most outstanding achievements in 20 years of breeding work. Our work is the first research devoted to < 90RM germplasm enhancement with incorporation of tropical and latetemperate genetic materials for unique inbred line development. Adding unique genetic diversity through this methodology will definitively reduce our vulnerability to climate changes. At the same time, the sustainability of maize production will increase serving as a model for other cereal crops, where breeders often are not ready to take the risks associated with broadening the genetic base. It is in our plans to test new early-maturing EarlyGEM breeding populations to increase our efforts to identify alternative heterotic patterns for the northern U.S. Corn Belt (Carena and Hallauer 2001a, b, Carena 2005a, Melani and Carena 2005, Carena and Wicks III 2006, Jumbo and
Carena 2008), identify unique groups of genetic diversity for grain quality (Osorno and Carena 2008), and continue the development of new and unique lines not present in industry (Table 1).

\section{MOVING MAIZE WEST: SHORT-SEASON DROUGHT TOLERANCE}

Extreme temperatures during the growing season are a challenge for maize production and a major consequence of climate changes. Therefore, breeding efforts focused on improving tolerance to abiotic stresses is desirable and currently needed to develop cultivars stable to environmental changes.

Yield and quality losses are maximized when drought occurs during flowering time in maize. In the absence of stress, tolerance mechanisms often have a significant grain yield penalty but a stability advantage. The use of reliable locations where stress intensity can be managed has made significant improvement for breeding purposes. Reliable drought locations increase the accuracy of genetic estimates in which drought associate traits can be measured (Bolanos and Edmeades 1996, Carena et al. 2009b). Drought tolerance is genetically a very complex trait with large genotype by environment interactions. Therefore, markerassisted selection and transgenic approaches are challenging. Non-transgenic breeding approaches have a potential of significantly increasing genetic progress exploiting polygenic effects compared to transgenic approaches exploiting single-gene effects.

Maize has a wide range of adaptation. However, ND maize is still limited in its extension to the west due to significant environmental challenges mainly drought. Since 2001, irrigation in drought-managed winter nurseries has been designed so that drought at flowering time is severe enough to delay silking simulating the drought stress that is relevant in western ND. Anthesis-silk interval (ASI) is collected on lines per se while agronomic data including grain yield is collected on testcross hybrid trials between commercial testers and the most drought tolerant lines to exploit heterotic combinations. Summer trials are conducted under both dry land and irrigated environments at target environments. The results of this program enhance our ability for a better maize-ethanol relationship. Without harvestable good quality products efficient ethanol production will continue to be only a potential in drought affected areas. Western ND is the extreme example of short-season drought. In fact, ethanol plants have 


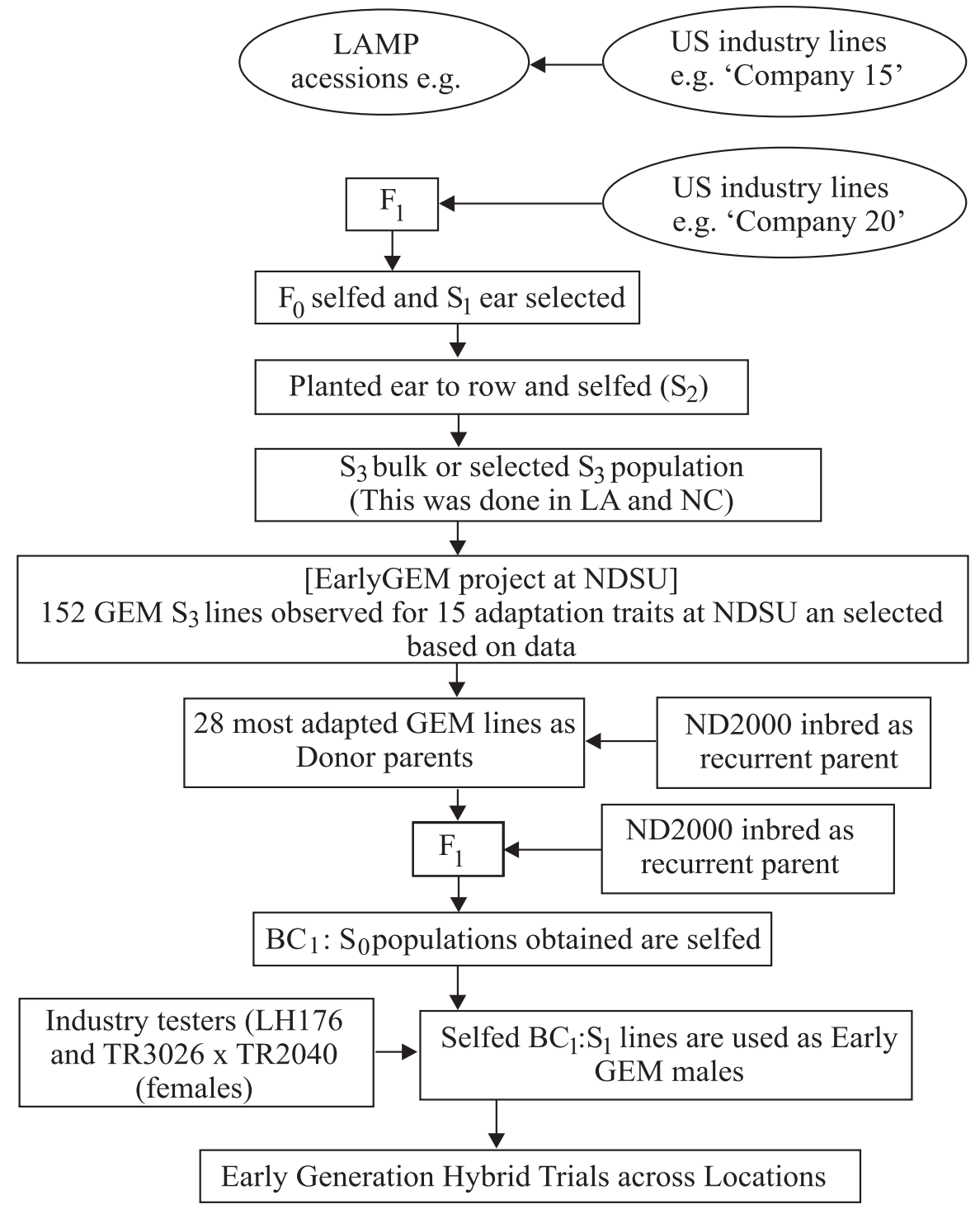

Figure 3. NDSU EarlyGEM: Extension of the LAMP-GEM to develop new short-season products.

established where relatively cheap energy sources are present (e.g., coal and oil in western ND). The development of elite maize hybrids with improved stress tolerance is essential to obtain maximum yields and minimum costs associated with production and the environment. Preliminary data of early and late generation hybrid trials in western ND and eastern Montana (MT) showed that hybrids including NDSU experimental lines had significantly better yield, lower grain moisture at harvest, higher test weight, higher extractable starch, higher fermentable starch, higher oil, and higher protein than industry check hybrids (Carena et al. 2009b). At least 40 NDSU experimental hybrids yielded better than checks in western ND with specific hybrids exceeding $193.8 \%$ yield improvement considering dry land and irrigated conditions. Several of these have exotic alleles in their genetic background as they belong to our NDSU EarlyGEM inbred line development program for short-season environments. There is no limit to genetic improvement for drought tolerance when most tolerance genes are targeted in the breeding process. Heterotic effects are unique for each hybrid and sequencing efforts on only B73 may limit the identification of useful alleles for drought tolerance and other complex traits as well. Transgenic drought tolerant industry hybrids are not 
Table 1. Means combined over ND environments of six traits for selected top performing entries sorted by yield for EarlyGEM-derived maize hybrids

\begin{tabular}{|c|c|c|c|c|c|c|}
\hline Hybrid & $\begin{array}{c}\text { Grain } \\
\text { yield } \\
\text { (bu/A) }\end{array}$ & $\begin{array}{c}\text { Grain } \\
\text { moisture } \\
(\%)\end{array}$ & $\begin{array}{l}\text { Root } \\
\text { Ldg } \\
(\%)\end{array}$ & $\begin{array}{l}\text { Stalk } \\
\text { Ldg } \\
(\%)\end{array}$ & $\begin{array}{c}\text { Test } \\
\text { weight } \\
\text { (lb/bu) }\end{array}$ & $\begin{array}{c}\text { Emergence } \\
(\%)\end{array}$ \\
\hline LH176 X ND2002 & 165.7 & 19.7 & 0.9 & 3.8 & 56.6 & 0.70 \\
\hline LH176XND07-209 & 165.0 & 20.3 & 0.0 & 0.9 & 55.8 & 0.65 \\
\hline LH176XND07-260 & 162.2 & 19.9 & 0.7 & 1.8 & 56.9 & 0.65 \\
\hline LH176XND07-228 & 159.5 & 20.0 & 0.0 & 1.5 & 56.9 & 0.75 \\
\hline ND07-226XLH176 & 159.8 & 20.2 & 0.0 & 7.3 & 58.0 & 0.61 \\
\hline LH176XND07-207 & 155.7 & 20.7 & 0.0 & 1.8 & 55.9 & 0.63 \\
\hline LH176XND07-252 & 155.7 & 23.8 & 0.0 & 5.5 & 53.6 & 0.64 \\
\hline ND07-207XLH176 & 152.1 & 21.0 & 1.6 & 5.8 & 55.2 & 0.65 \\
\hline TR3026 Bt X TR1957 & 151.8 & 20.9 & 0.0 & 0.8 & 57.3 & 0.70 \\
\hline ND07-210XLH176 & 151.7 & 19.7 & 0.5 & 3.8 & 55.8 & 0.68 \\
\hline LH176XND07-255 & 149.9 & 19.2 & 2.6 & 2.0 & 56.7 & 0.64 \\
\hline LH176XND07-244 & 149.5 & 21.5 & 1.2 & 0.5 & 54.5 & 0.62 \\
\hline LH176XND07-249 & 149.3 & 20.0 & 0.0 & 2.8 & 56.5 & 0.64 \\
\hline LH176XND07-205 & 149.0 & 19.8 & 0.0 & 4.7 & 55.7 & 0.63 \\
\hline LH176XND07-236 & 148.2 & 19.8 & 0.0 & 3.5 & 56.4 & 0.61 \\
\hline LH176XND07-241 & 147.9 & 21.1 & 0.0 & 5.1 & 55.6 & 0.65 \\
\hline Pioneer 39D82 & 146.8 & 18.1 & 0.0 & 2.2 & 56.1 & 0.56 \\
\hline LH176XND07-256 & 146.6 & 19.1 & 0.0 & 6.5 & 58.0 & 0.67 \\
\hline LH176XND07-218 & 146.6 & 20.4 & 0.0 & 3.3 & 56.6 & 0.62 \\
\hline TR3621Bt X TR3273 & 145.1 & 20.8 & 0.0 & 2.4 & 58.2 & 0.65 \\
\hline Mean & 138.1 & 20.1 & 0.3 & 3.8 & 56.3 & 0.64 \\
\hline CV $(\%)$ & 10.8 & 4.9 & 359.8 & 83.3 & 2.2 & 9.28 \\
\hline $\operatorname{LSD}(0.05)$ & 22.2 & 3.3 & 1.3 & 5.2 & 1.4 & 0.11 \\
\hline
\end{tabular}

${ }^{1}$ ND07 = (AR16026:S17-66-1-B x ND2000) x ND2000. Selected top performing entries of partially-balanced lattice experiments.

yet available for use as checks in western ND and eastern MT short-season trials. This is an area not served by industry yet and the public sector still is essential. In the meantime, the NDSU program is helping produce a sustainable crop under intense drought for a better utilization by ethanol plants without additional transportation and fossil fuel costs. The NDSU maize population-hybrid concept has been recognized as a profitable alternative method of maize hybrid production (Carena 2005a, Carena and Wicks III 2006) and it is currently being tested commercially in central and western ND for ethanol utilization.

\section{THE FUTURE: DEVELOPING BREEDING METHODS AND CULTIVARS FORADAPTATION TO CLIMATE CHANGES}

The NDSU maize breeding program currently has over 20 programs undergoing recurrent selection for germplasm enhancement in ND environments. These include a diverse set of breeding methods (e.g., half-sib and full-sib intra and inter-population programs with and without testers, etc.) and have the purpose to:

1) Enhance germplasm for adaptation to climate changes;

2) Maximize genetic improvement of geneticallybroad base sources of short-season cultivars; and

3) Educate the next generation of breeders

NDSU conducts maize breeding for high extractable starch under drought and cold stresses as well as for high quality protein and fast drying maize to develop the next generation of healthier and safer products. Mating designs and incorporation programs that allow large sampling of populations, inbred lines, and hybrids do generate extremely useful information for marketing the next generation of products adapted to climate changes.

Adaptation to climate changes requires improvement of traits that are quantitatively inherited largely influenced by the environment. These traits are often controlled by hundreds of genes and their interactions and are difficult to measure. Ideas to overcome the evaluations of such 
traits should be a priority. A new screening technique (AUDDC-area under the dry down curve) was proposed to identify faster drier corn products (Yang et al. 2010). This method has demonstrated to be accurate and reliable and industry is already utilizing it. The NDSU maize program has been recognized for its development toward helping save billions of dollars to drying maize. This preliminary discovery is still under test and it is one of the first tools to measure this complex trait in a simple and accurate way. This method can be extended to all areas of maize production to reduce the impact of climate changes on crops.

Cold tolerance efforts have allowed us to make progeny selection progress at a rate of one season per year identifying progenies with high levels of cold tolerance (Sezegen and Carena 2009). The identification of screening locations (e.g., high MT elevations with snow and frost even in July and southern winter nursery cold-managed environments) has allowed us to find cold tolerant products currently demanded by industry. Similar efforts have been utilized on developing salt tolerant inbred lines through controlled greenhouse and field conditions. These projects will help prevent crop damages that could be cause by extreme climate change environmental conditions.

Maize is the principal energy source in many feed rations. Enhancement of quality protein traits in shortseason germplasm will provide added value to the U.S. northern Corn Belt farmers and ranchers. NDSU EarlyGEM populations have been developed for different traits (starch, protein, and oil). However, further enhancements have been initiated to improve the quality of these traits under climate change environments. Among the most limiting amino acids in feed ingredients are lysine, methionine, and cysteine. A diallel mating design was produced with 16 diverse maize populations adapted to ND environmental conditions and currently undergoing different NDSU intra and inter-population recurrent selection programs. Preliminary data were generated in partially balanced single lattice experiments across ND locations in 2010. Four of the most outstanding populations were recently developed at NDSU and are part of an extensive recurrent selection program: NDSS (North Dakota Stiff Stalk Synthetic), NDL (North Dakota Lancaster), ND1011, and EarlyGEM 21 (NDSU EarlyGEM 21 synthetic variety). The latter was developed from the top backcross derived lines including $75 \%$ the elite short-season line ND2000 and 25\% Argentinian maize accession. Genetically broad-based ND populations provide not only unique groups of genetic variability with local adaptation but also competitive sources for the next generation of healthier maize products. Quality protein traits are also being evaluated, for the first time, in shortseason quality protein maize germplasm recently developed (>40 BC $\mathrm{BC}_{1}: \mathrm{S}_{1}$ populations) through the NDSU EarlyQPM Program in a similar procedure to the NDSU EarlyGEM Program) and in Indigenous maize varieties from several U.S. northern tribes. NDSU has cooperated with Indigenous reservations for 12 years with the purpose to prevent the extinction of varieties.

Maize breeding is a confidential business. Inbred lines are the 'secret formula' and are under restricted use because they are protected by U.S. Patent and/or the U.S. Plant Variety Protection Act (PVPA). Others are becoming available and their usefulness needs to be tested. Even though grain yield performance was not above top performing checks, test weight and grain quality traits were better than checks in certain hybrid combinations not tested before. About 500 hybrids will be evaluated in multiple ND environments (locations and years) according to four partially balanced lattice experimental designs.

Obtaining maximum yields in maize often requires a reduction in groundwater supplies due to irrigation and significant costs associated with production and the environment. Breeders can increase the sustainability of maize production and its vast genetic resources under variable climates through the development of cultivars with less input needs (e.g., not only drought tolerant but also tolerant to low $\mathrm{N}$ needs). We have identified cost/effective, and less input oriented breeding strategies to optimize water under extreme conditions. We intend to identify the ones for $\mathrm{N}$ use efficiency under similar conditions based on the principles addressed by Carena et al. (2009a). Certain genotypes have demonstrated to be more stable across environments which should be more tolerant to climate change (Carena et al. 1998). Tolerance to low inputs is one of these important unsolved dilemmas between breeding and sustainable row-crop maize production. For instance, most (if not all) scientists have decided to grow and evaluate maize hybrids under low nitrogen $(\mathrm{N})$ and/or organic environments. The problem with this approach is that currently available maize hybrids have been bred under high $\mathrm{N}$ and conventional environments. Banziger et al. (1999) found an interesting relationship between drought tolerance and response to nitrogen use efficiency showing that genotypes potentially adapted to climate change might be more stable across extreme environments. What are 


\section{MJ Carena}

the chances to find genotypes that are top performers under sustainable conditions if interactions are present? It is, therefore, necessary to evaluate genotype $\mathrm{x} \mathrm{N}$ and genotype $\mathrm{x}$ soil type interactions to determine the need/ lack of need for duplicating cultivar development programs under different environmental conditions. We have previously determined that no interactions are present when testing different plant densities and tillage systems in maize (Carena and Cross 2003, Hyrkas and Carena 2005, Carena et al. 2009a). We have the opportunity to challenge current and past production research by addressing the real facts behind sustainability. How costly and environmental friendly should a technology be to achieve a profitable and sustainable maize crop? What kind of maize hybrids is currently available for a sustainable maize production? These and other questions reflect a number of unsolved dilemmas present in maize breeding and production research for climate changes.

\section{CONCLUSIONS}

There is a need for projects addressing the adaptation of cereal production systems to climate changes through breeding for local adaptation in unique environments, maximizing genetic improvement, and developing new cultivars that are stable to environmental changes. The NDSU maize breeding program is an example of the integration of germplasm adaptation to climate change with cultivar development. It focuses on the long-term viability and sustainability of maize production adapted to climate changes and exploits unique environments that can actually screen genotypes for these future problems. Longterm activities to adapt and maximize genetic improvement of elite germplasms under climate changes are required. These germplasms are sources of unique cultivars that will meet the $21^{\text {st }}$ century demands of food, feed, fuel, and fiber in environments with climate changes. However, these key activities have received less attention due to few active public breeding programs left in the nation and overseas. These programs are the only ones that can meet future changes in environmental effects and applied plant breeding capacity building will be essential (Guimaraes et al. 2006).

\section{Aprimoramento de germoplasma para adaptação às mudanças climáticas}

RESUMO - Bilhões em dólares e em cultivos estão sendo desperdiçados, seja durante a secagem de grãos ou ainda devido à suscetibilidade à seca, ao frio, à condições salinas de cultivo e ao processamento de grãos de baixa qualidade. O milho é um modelo de cultivo para adaptação a mudanças no clima. O melhoramento para adaptação é mais eficiente quando é conduzido em condições de desafios ambientais nas quais os genótipos mais adaptados são prontamente identificados e os mais estáveis são selecionados. O programa de melhoramento de milho da Universidade Estadual de Dakota do Norte (NSDU), nos Estados Unidos, está estrategicamente localizado para desenvolver produtos sob condições de clima extremo. Esse programa atualmente aproveita os ambientes do norte dos Estados Unidos que permitem avaliar germoplasma para caracteres de adaptação importantes como produção. O programa dá ênfase em adaptação de germoplasma e sua integração com o desenvolvimento de cultivar, particularmente aquelas que possuem alelos singulares que não estejam presentes nos genomas B73 e NAM. Projetos que enfoquem as demandas presentes e futuras por genótipos superiores que sejam tolerantes a mudanças climáticas nos Estados Unidos e em várias parte do mundo são vitais para a pesquisa agrícola.

Palavras-chave: adaptação, desenvolvimento de cultivares, diversidade genética, melhoramento de milho, NSDU EarlyGEM.

\section{REFERENCES}

Banziger M, Edmeades GO and Lafitte HR (1999) Selection for drought tolerance increases maize yields across a range of nitrogen levels. Crop Science 39: 1035-40.
Barata C and Carena MJ (2006) Classification of North Dakota maize inbred lines into heterotic groups based on molecular and testcross data. Euphytica 151: 339-249. 
Bolanos JS and Edmeades GO (1996) The importance of the anthesis-silk interval in breeding for drought tolerance in tropical maize. Field Crops Research 48: 65-80.

Carena MJ (2005a) Maize commercial hybrids compared to improved population hybrids for grain yield and agronomic performance. Euphytica 141: 201-208.

Carena MJ (2005b) Registration of NDSAB(MER-FS)C13 maize germplasm. Crop Science 45: 1670-1671.

Carena MJ and Cross HZ (2003) Plant density and maize germplasm improvement in the northern corn belt. Maydica 48: $105-111$

Carena MJ and Hallauer AR (2001a) Response to inbred progeny recurrent selection in Leaming and Midland Yellow Dent populations. Maydica 46: 1-10.

Carena MJ and Hallauer AR (2001b) Expression of heterosis in Leaming and Midland Yellow Dent populations. Journal of Iowa Academic Science 108: 73-78.

Carena MJ and Wanner DW (2003) Registration of ND2000 inbred line of maize. Crop Science 43: 1568-1569.

Carena MJ and Wanner DW (2009) Development of genetically broad-based inbred lines of maize for early maturing (70-80RM) hybrids. Journal of Plant Registrations 3: 107-111.

Carena MJ and Wicks III ZW (2006) Maize early maturing hybrids: an exploitation of U.S. temperate public genetic diversity in reserve. Maydica 51: 201-208.

Carena MJ, Eno C and Wanner DW (2008) Registration of NDBS11(FR-M)C3, NDBS1011, and NDBSK(HI-M)C3 maize germplasms. Journal of Plant Registrations 2: 132-136.

Carena MJ, Santiago I and Ordas A (1998) Direct and correlated response to selection for prolificacy in maize at two planting densities. Maydica 43: 95-102.

Carena MJ, Wanner DW and Cross HZ (2003) Registration of ND291 inbred line of maize. Crop Science 43: 15-68.

Carena MJ, Wanner DW and Yang J (2010) Linking pre-breeding for local germplasm improvement with cultivar development in maize breeding for short-season (85-95RM) hybrids. Journal of Plant Registration 4: 86-92.

Carena MJ, Yang J, Caffarel, JC, Mergoum M and Hallauer AR (2009a) Do different production environments justify separate maize breeding programs? Euphytica 169: 141-150.

Carena MJ, Bergman G, Riveland N, Eriksmoen E and Halvorson M (2009b) Breeding maize for higher yield and quality under drought stress. Maydica 54: 287-296.

Carena MJ, Pollak L, Salhuana W and Denuc M (2009c) Development of unique lines for early-maturing hybrids: Moving GEM germplasm northward and westward. Euphytica 170: 87 97.

Crop Breeding and Applied Biotechnology S1: 56-65, 2011
Eno C and Carena MJ (2008) Adaptation of elite temperate and tropical maize populations to North Dakota. Maydica 53: 217-226

Goodman MM (1965) Estimates of genetic variance in adapted and exotic populations of maize. Crop Science 5: 87-90.

Griffing B and Lindstrom EW (1954) A study of combining abilities of corn inbreds having varying proportions of Corn Belt and non-Corn Belt germplasm. Agronomy Journal 46: 845-52.

Guimaraes E, Kueneman E and Carena MJ (2006) Assessment of national plant breeding and biotechnology capacity in Africa and recommendations for future capacity building. Horticultural Science 41: 50-52.

Hallauer AR and Carena MJ (2009) Maize breeding. In Carena MJ (ed.) Handbook of plant breeding: cereals. Springer, New York, p. 3-98.

Hallauer AR, Miranda Fo JB and Carena MJ (2010) Quantitative genetics in maize breeding. $3^{\text {rd }}$ ed., Springer, New York, $663 \mathrm{p}$.

Hyrkas A and Carena MJ (2005) Response to long-term selection in early maturing maize synthetic varieties. Euphytica 143: 43-49.

Jumbo MB and Carena MJ (2008) Combining ability, maternal, and reciprocal effects of elite early-maturing maize population hybrids. Euphytica 162: 325-333.

Melani MD and Carena MJ (2005) Alternative heterotic patterns for the northern corn belt. Crop Science 45: 2186-2194.

Osorno J and Carena MJ (2008) Creating groups of maize genetic diversity for grain quality: Implications for breeding. Maydica 53: 131-141.

Rinke EH and Sentz JC (1961) Moving corn belt dent germplasm northward. Minnesota Agricultural Experimental Station 1110: 53 .

Sezegen B and Carena MJ (2009) Divergent recurrent selection for cold tolerance in two improved maize populations. Euphytica 167: 237-244.

Sonnino A, Carena MJ, Guimaraes EP, Baumung R, Pilling D and Rischkowsky B (2007) An assessment of the use of molecular markers in developing countries. In Guimaraes EP, Ruane J, Scherf BD, Sonino A and Dargie JD (eds.) Marker-assisted selection: current status and future perspectives in crops, livestock, forestry, and fish. FAO, Rome, p. 15-26.

Yang J, Carena MJ and Uphaus J (2010) AUDDC: A method to evaluate rate of dry down in maize. Crop Science 50: 1-8. 